\title{
Cercosporin From Pseudocercosporella capsellae and its Critical Role in White Leaf Spot Development
}

Niroshini Gunasinghe, Ming Pei You, Gregory R. Cawthray, and Martin J. Barbetti, School of Plant Biology and the UWA Institute of Agriculture, Faculty of Science, The University of Western Australia, Crawley, WA 6009, Australia

\begin{abstract}
Gunasinghe, N., You, M. P., Cawthray, G. R., and Barbetti, M. J. 2016. Cercosporin from Pseudocercosporella capsellae and its critical role in white leaf spot development. Plant Dis. 100:1521-1531.

Pseudocercosporella capsellae, the causative agent of white leaf spot disease in Brassicaceae, can produce a purple-pink pigment on artificial media resembling, but not previously confirmed as, the toxin cercosporin. Chemical extraction with ethyl acetate from growing hyphae followed by quantitative (thin-layer chromatography [TLC] and high-performance liquid chromatography [HPLC]) and qualitative methods showed an identical absorption spectrum, with similar retardation factor (Rf) values on TLC papers and an identical peak with the same retention time in HPLC as for a standard for cercosporin. We believe this is the first report to confirm that the purplepink pigment produced by $P$. capsellae is cercosporin. Confocal microscopy detected green autofluorescence of cercosporin-producing hyphae, confirming the presence of cercosporin inside hyphae. The highly virulent UWA Wlra-7 isolate of $P$. capsellae produced the greatest quantity of cercosporin $\left(10.69 \mathrm{mg} \mathrm{g}^{-1}\right)$. The phytotoxicity and role of cercosporin in disease initiation across each of three Brassicaceae host species (Brassica juncea, B. napus,

and Raphanus raphanistrum) was also studied. Culture filtrates containing cercosporin were phytotoxic to all three host plant species, producing large, white lesions on highly sensitive $B$. juncea, only water-soaked areas on least sensitive $R$. raphanistrum, and intermediate lesions on B. napus. It is noteworthy that sensitivity to cercosporin of these three host species was analogous to their susceptibility to the pathogen, viz., B. juncea the most susceptible, $R$. raphanistrum the least susceptible, and B. napus intermediate. The presence of cercosporin in the inoculum significantly increased disease severity on the highly cercosporin-sensitive $B$. juncea. We believe that this is the first study to demonstrate that $P$. capsellae produces cercosporin in liquid culture rather than agar media. Finally, this study highlights an important role of cercosporin as a pathogenicity factor in white leaf spot disease on Brassicaceae as evidenced by the ability of the cercosporin-rich culture filtrate to reproduce white leaf spot lesions on host plants and by the enhanced virulence of $P$. capsellae in the presence of cercosporin.
\end{abstract}

White leaf spot caused by the fungal pathogen Pseudocercosporella capsellae can result in considerable yield loss across a wide range of brassicas (Brun and Tribodet 1991). For example, severe infections from $P$. capsellae result in significant damage to oilseed rape (Barbetti and Khangura 2000; Inman 1992; Penaud 1987; Petrie and Vanterpool 1978), species utilized as forage brassicas (Marchionatto 1947; Ocamb 2014) and/or vegetable brassicas (Campbell and Greathead 1978; Cerkauskas et al. 1998; Reyes 1979). In Australia, white leaf spot is considered an important disease across different oilseed brassicas; it has been reported from all oilseed growing areas (Barbetti and Khangura 2000; Barbetti and Sivasithamparam 1981; Hamblin et al. 2004), and severe losses occur in highly susceptible varieties (up to 30\%) (Barbetti and Khangura 2000) or when favorable environmental conditions for disease development occur (Hamblin et al. 2004; Henry and Steve 2014). P. capsellae belongs to the family Mycosphaerellaceae that contains the causal agents of several economically important crop and tree diseases, and this pathogen has a sexual stage known as Mycosphaerella capsellae.

This pathogen is known to produce a purple-pink phytotoxic compound resembling cercosporin (Petrie and Vanterpool 1978). Cercosporin is a light-activated (Yamazaki et al. 1975), nonspecific, universal toxin (Tamaoki and Nakano 1990) from many species of Cercospora (Assante et al. 1977). It was first isolated by Kuyama and Tamura (1957) from Cercospora kikuchii causing a purple stain disease of soybean and subsequently from other Cercospora pathogens (Balis and Payne 1971; Blaney et al. 1988; Fajola 1978; Guchu and Cole 1994; Mumma et al. 1973; Tessmann et al. 2008; Venkataramani

Corresponding author: Martin J. Barbetti; E-mail: martin.barbetti@uwa.edu.au Accepted for publication 28 February 2016.

http://dx.doi.org/10.1094/PDIS-10-15-1192-RE

(C) 2016 The American Phytopathological Society
1967). Many studies have been undertaken to determine its structure and chemistry (Kuyama 1962; Lousberg et al. 1971; Nasini et al. 1982), biology (Daub and Ehrenshaft 2000), modes of action (Cavallini et al. 1979; Daub 1982; Dobrowolski and Foote 1983; Hartman et al. 1988; Leisman and Daub 1992), contribution to pathogenesis (Daub 1987; Steinkamp et al. 1981; Upchurch et al. 1991, 2005), gene expression (Choquer et al. 2007; Shim and Dunkle 2002), resistant genes (Daub and Ehrenshaft 2000), regulation of in vitro production (Jenns et al. 1989; You et al. 2008), and resistant mechanisms to the toxin itself (Daub et al. 1992, 2000).

Cercosporin is a naturally occurring dihydroxy-perylenequinone $\left(\mathrm{C}_{29} \mathrm{H}_{26} \mathrm{O}_{10}\right)$ (Kuyama 1962; Lousberg et al. 1971; Yamazaki and Ogawa 1972) known to cause toxic effects on plants (Balis and Payne 1971; Fajola 1978) and bacteria (Fajola 1978; Okubo et al. 1975). Cercospora isolates secrete cercosporin into host tissues during infection processes (Daub and Ehrenshaft 2000; Fajola 1978; Venkataramani 1967). While Fajola (1978) extracted cercosporin from diseased lesions across 16 different hosts, $P$. capsellae isolates that did not show any indication of producing cercosporin were still pathogenic to Brassicaceae hosts (Gunasinghe et al. 2016). However, Upchurch et al. (1991) demonstrated that some isolates unable to produce cercosporin on artificial culture media could do so in planta. Therefore, it is evident that the production and/or role of cercosporin in disease development is complex and conclusions cannot be made based solely on cultural studies (Daub and Ehrenshaft 2000).

The production of a purple-pink pigment by $P$. capsellae in vitro had been assumed as cercosporin by Petrie and Vanterpool (1978) and later by others (Eshraghi et al. 2005; Okullo'kwany 1987). While several other Cercospora spp. are confirmed to produce cercosporin, there is, however, contrasting evidence that pigments produced by Cercospora spp. are not always cercosporin (Fore et al. 1988). This lack of information on the chemical nature of the pigment produced by $P$. capsellae is puzzling, given that relevant methodologies are available. Hence, we undertook studies to clarify the identity, nature, and role of the purple-pink pigment produced by 
P. capsellae, first, to chemically identify it, second, to evaluate its phytotoxicity across three Brassicaceae species (Brassica juncea, B. napus, and Raphanus raphanistrum) and, third, to determine its role in disease initiation.

\section{Materials and Methods}

Isolates. Single-spored, pigment-producing isolates of $P$. capsellae representing four different isolate groups obtained from white leaf spot lesions in Western Australia were used, viz. UWA Wlra-7, UWA Wlj-3, UWA Wln-9, and UWA Wlr-8 (Gunasinghe et al. 2016). UWA Wln-9 was from B. napus at Bindoon North, UWA Wlra-7 was from $R$. raphanistrum at West Calingiri, while isolates UWA Wlj-3 and UWA Wlr-8 were from $B$. juncea from The University of Western Australia's Field Research Station at Shenton Park and B. rapa from Perth, respectively. Following initial isolation, all isolates were lyophilized and stored in ampoules at room temperature. When experiments were initiated, each isolate was revived by subculturing onto plates of freshly prepared malt extract agar (MEA: malt extract $20.0 \mathrm{~g} \mathrm{liter}^{-1}$, glucose $20.0 \mathrm{~g} \mathrm{liter}^{-1}$, agar $15.0 \mathrm{~g} \mathrm{liter}^{-1}$, and peptone $1.0 \mathrm{~g} \mathrm{liter}^{-1}$ ). Working cultures were maintained as MEA slants at $4^{\circ} \mathrm{C}$.

In vitro production of cercosporin. Each isolate was subcultured onto freshly prepared sterilized MEA medium from the cultures maintained at $4{ }^{\circ} \mathrm{C}$. After 2 weeks incubation at $20^{\circ} \mathrm{C}$, the mycelial fragments from growing edges of each culture were aseptically transferred into separate Erlenmeyer flasks $(250 \mathrm{ml})$ containing $150 \mathrm{ml}$ of malt extract broth (MEB: malt extract $20.0 \mathrm{~g} \mathrm{liter}^{-1}$, glucose $20.0 \mathrm{~g}$ $\operatorname{liter}^{-1}$, peptone $1.0 \mathrm{~g} \mathrm{liter}^{-1}$ in distilled water). Then, cultures were incubated on a rotary platform shaker (Innova 2100, New Brunswick Scientific) maintained at $150 \mathrm{rpm}$ at $22^{\circ} \mathrm{C}$ under white fluorescence light for up to 5 weeks until the color of the culture turned purple. Morphology of the mycelium was observed by preparing wet mounts of cultures on glass slides. Mycelium was placed in a drop of distilled water and examined under an Olympus (BX51) microscope using both UV excitation and brightfield modes. Imagers were captured with an Olympus DP71 digital photographic system.

Confocal microscopy for hyphae growing on an agar. Agar plugs (four replicates each) of isolate UWA Wlra-7 were aseptically transferred on to a freshly prepared MEA plates and incubated for 3 weeks in an incubator at $20^{\circ} \mathrm{C}$ under cool florescence white light. Hyphae producing cercosporin (as indicated by purple-pink color of the underside of the colony and the culture border area) were mounted on a water drop on a glass slide and visualized under a Leica TCS SP2 AOBS laser scanning confocal microscope. All fluorescent images were taken using the $488 \mathrm{~nm}$ and $561 \mathrm{~nm}$ laser lines to detect the auto-florescence of the hyphae and cercosporin, respectively. The color of each channel was assigned by the Leica SP2 software. At each confocal plane, a resolution of $1,024 \times 1,024$ pixels and a scanning speed of $400 \mathrm{~Hz}$ with a $40 \times$ objective was utilized. Superimposing the two channels of each confocal plane generated the images. Stacking these superimposed images generated the final images. Approximately 14 confocal sections that covered the entire depth of view for hyphae were acquired and fixed maximum projections of stacks generated using Leica software. All images were taken using the same settings for laser power, gain, and offset.

Pigment extraction and cercosporin standard. Isolate UWA Walra-7 was selected for extraction of pigment as it produced the greatest amount of pigment as indicated by the dark purple color of the broth culture. Broth culture with abundant mycelial growth was filtered through double layered cheesecloth to separate the mycelium. Wet mycelium (1 g) was blended with Stick Mixer (HB1913-C) in $20 \mathrm{ml}$ of ethyl acetate (EtoAc) and the crude extract separated from mycelial debris by decanting into a $50 \mathrm{ml}$ centrifuge tube. Pigment extract for further analysis was then obtained by centrifuging the crude extract at 2,800 rpm for $30 \mathrm{~min}$ in a hanging bucket centrifuge (Eppendorf Centrifuge 5810) and collecting the particle-free clear supernatant.

Thin layer chromatography (TLC), UV/visible spectrum, and high-performance liquid chromatography (HPLC) analyses. It was hypothesized that the dark purple or purple-pink pigment produced by $P$. capsellae isolates on MEB or MEA, respectively, was cercosporin as evidenced by the respective colors. Hence, initial pigment extract was compared with cercosporin standard (purchased from Sigma-Aldrich, Germany) is from a well-known cercosporin producer C. kikuchii (Mumma et al. 1973) and using three different methods to confirm the identity of the pigment as cercosporin.

The pigment extract was resolved by TLC using precoated plates of aluminum backed, $200 \mu \mathrm{m}$ thick silica gel, with indicator F-254 (Silicycle Inc, Canada). A total of $5 \mu$ l of pigment extract and standard cercosporin were spotted on to a TLC plate $(5 \times 9 \mathrm{~cm})$ with $1 \mathrm{~cm}$ distance between spots. The first and second spots were $5 \mu l$ of standard cercosporin and pigment extract from the mycelium. The third spot was spotted as a combination of standard and pigment extract $(2.5 \mu \mathrm{l}$ each) and pure EtoAc as a blank was the last (fourth) spot. Spots were air dried and TLC plate was developed with chloroform/ethanol/water (80:20:2 v/v) as the developing solvent in a small glass tank lined with chromatography paper equilibrated with the running solvent. Developed chromatography paper with purple-pink spots was air dried before calculating retardation factor (Rf) values. All the studies were carried out at room temperature. To confirm findings, three identical repeat runs were undertaken with the same conditions, but swapping the position of each spot.

The UV/visible spectrums for the cercosporin standard and the crude pigment extract, both in EtoAc, were obtained using a Cary 3 UV visible spectrophotometer (Varian Instruments Group, Palo Alto, CA) with a wavelength scan range of 280 to $700 \mathrm{~nm}$. The absorption maxima were read for both using EtoAc as a blank.

The pigment extract was compared with the cercosporin standard using HPLC to identify the pigment present in the extract. Analysis of cercosporin was adapted from Milat and Blein (1995) and undertaken using a Waters (Milford, MA) high performance liquid chromatograph (HPLC) consisting of 600E pump, 717plus autoinjector, a 470 scanning fluorescence detector, and a 996 photodiode array (PDA) detector. Separation was performed on a Waters Atlantis C18 column ( $150 \mathrm{~mm} \times 4.6 \mathrm{~mm}$ I.D. $)$ with $5 \mu \mathrm{m}$ particle size, held at $30 \pm 0.5^{\circ} \mathrm{C}$. A gradient mobile phase consisting of eluent A (acetonitrile with 5\%, v/v, acetic acid) and eluent B (Milli-Q water with $5 \%, \mathrm{v} / \mathrm{v}$, acetic acid) at a flow rate of $1.5 \mathrm{ml} \mathrm{min}^{-1}$ was used. An initial linear gradient from 50 to $70 \%$ eluent $\mathrm{A}$ over the first $8 \mathrm{~min}$ was followed by isocratic at $70 \%$ eluent $A$ for 1 min before an immediate change to $100 \%$ eluent $\mathrm{A}$. The mobile phase of $100 \%$ eluent A was maintained for $6 \mathrm{~min}$, before immediate change back to $50 \%$ eluent A for 10 min column re-equilibration. All solvents were vacuum filtered to $0.22 \mu \mathrm{m}$ prior to use and were continually degassed with helium sparging. Samples in the auto-injector were held at $10^{\circ} \mathrm{C}$.

All data were acquired and processed with Empower chromatography software (Waters) with fluorescence detector settings of $500 \mathrm{~nm}$ excitation, $623 \mathrm{~nm}$ emission, and the PDA set to $470 \mathrm{~nm}$ for quantification with a scan range of 205 to $700 \mathrm{~nm}$. Positive identification of cercosporin was accomplished by comparing standard retention time for fluorescence and PDA peak area ratios of the two detectors as well as PDA peak spectral analyses, including peak purity, with the samples. Typical injection volume for EtoAc extracts was $10 \mu$ l, but for samples of lower concentrations, the EtoAc extract was dried down under a stream of nitrogen and then redissolved in the initial mobile phase as detailed above. This allowed for injection volumes up to $100 \mu l$ to be used.

Calibration curves for cercosporin were generated from detector peak area vs. the mass of standard cercosporin injected, and a standard analyzed every 10 samples to check for any instrument/detector drift. Finally, the documented reactions of known cercosporin with series of chemicals were compared with dry residues of the pigment extract and standard cercosporin. Solubility and color differences were recorded in $\mathrm{KOH}$, $\mathrm{NaOH}, \mathrm{HCl}, \mathrm{H}_{2} \mathrm{O}, \mathrm{H}_{2} \mathrm{SO}_{4}$, and acetone and at high and low $\mathrm{pH}$ values.

In vivo production of cercosporin by $\mathrm{P}$. capsellae. This study was undertaken to confirm cercosporin production on the leaf surface during disease development. Cercosporin extractions were carried out from developing lesions of field inoculated plants belonging to two different susceptible host species, B. juncea (Rohin) and B. napus (Tyilogy).

Isolates (UWA Wlra-7, UWA Wlj-3, UWA Wlr-8, and UWA Wln-9) were inoculated into $150 \mathrm{ml} \mathrm{MEB}$ in $250 \mathrm{ml}$ Erlenmeyer flasks 
and incubated as described earlier. After 3 weeks incubation, cultures of all four isolates with abundant mycelial growth were mixed together in equal volumes and blended for $5 \mathrm{~min}$ (Kambrook, Mega Blender) to obtain a mixture of $P$. capsellae mycelial fragments at a concentration of $4 \times 10^{6}$ fragments $\mathrm{ml}^{-1}$.

Mycelial inoculum was used to induce disease in field grown plants as $P$. capsellae doesn't produce conidia on a wide variety of commonly used media (Crossan 1954; Miller and McWhorter 1948). Seeds of highly susceptible genotypes B. juncea Rohini and B. napus Trilogy (Gunasinghe et al. 2013) were sown in sequential batches of nine pots each (six seeds per pot). All pots were maintained in a controlled environment room $\left(15^{\circ} \mathrm{C}, 12 \mathrm{~h}\right.$ photoperiod, and a light intensity of $580 \mu \mathrm{mol}$ photons $\mathrm{m}^{-2} \mathrm{~s}^{-1}$ ) for 15 to 20 days and then transplanted into an experimental field plot $(1 \times 0.5 \mathrm{~m})$ at the University of Western Australia, Crawley. After transferring to the field, all plants were fertilized weekly with Thrive. At approximately
4 weeks of age, field plants were spray-inoculated with a mixture of mycelial fragments $\left(4 \times 10^{6}\right.$ fragments $\left.\mathrm{ml}^{-1}\right)$ from the three different isolates using a handheld and hand operated aerosol sprayer. Inoculations were repeated weekly for a further 3 weeks. All inoculations were conducted in the late afternoon to maximize the period of high humidity occurring naturally overnight. When disease symptoms became apparent, approximately 20 to 25 days post-inoculation (dpi), leaves with typical white leaf spot symptoms were collected separately.

Extraction of cercosporin from white leaf spot lesions. Developing lesions were then removed by cutting and separated from the rest of the leaf and freeze-dried (VirTis benchtop 2K, VirTis Co., Gardiner, NY). Pieces from healthy leaves from both species were also freezedried to serve as controls. Two samples each of $2 \mathrm{~g}$ were taken from each treatment (two species) and controls before grinding separately in $5 \mathrm{ml}$ EtoAc using a chilled mortar and pestle. The mixtures were then transferred to a $15 \mathrm{ml}$ centrifuge tube and cercosporin extracted into EtoAc
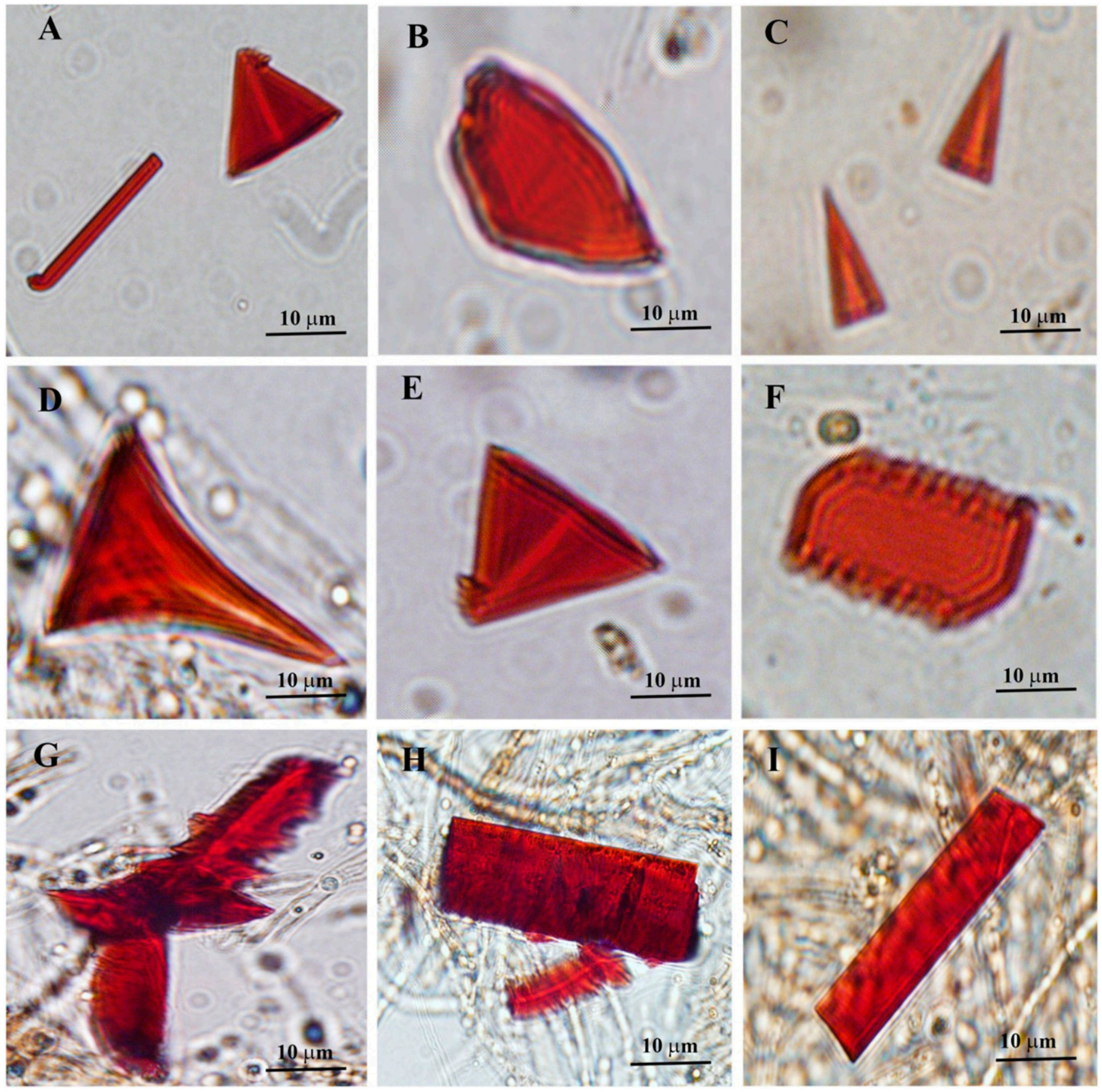

Fig. 1. Cercosporin crystals found in liquid culture of malt extract broth containing Pseudocercosporella capsellae isolate UWA Wlra-7 grown for 4 weeks on a rotary platform shaker maintained at $150 \mathrm{rpm}$ at $22^{\circ} \mathrm{C}$. A to $\mathrm{F}$, different individual crystal forms free floating in the broth culture. $\mathbf{G}$ to I, crystals and/or conglomerates (aggregates of crystals [G] also frequently appeared on the mycelial mat). 
overnight at $10^{\circ} \mathrm{C}$. Tubes were then centrifuged at 2,800 rpm for $30 \mathrm{~min}$ in a hanging bucket centrifuge (Eppendorf Centrifuge 5810) and supernatant collected. The extract (5 ml) was evaporated down to $2.5 \mathrm{ml}$ and analyzed for cercosporin by HPLC as described previously.

Phytotoxicity and role of cercosporin in different host species. For all inoculation studies, three isolates, viz. UWA Wln-9, UWA Wlj-3, and UWA Wlra-7 were used as either individual inocula or as a mixture of all three. The combination of isolates, UWA Wln-9 from B. napus, UWA Wlj-3 from B. juncea, and UWA Wlra-7 from $R$. raphanistrum, was used to avoid any contradictory outcome that may result by using only a single isolate derived from a specific host. Three host species were used, viz. mustard (B. juncea Rohini from India), oilseed rape (B. napus Trilogy from Australia), and R. raphanistrum (wild radish, the major Brassicaceae weed in canola fields in Western Australia), known to have differing susceptibilities to white leaf spot disease (Gunasinghe et al. 2016). For all inoculation studies, plants were grown in controlled environment rooms room at $15^{\circ} \mathrm{C}$, $12 \mathrm{~h}$ photoperiod with a light intensity of $580 \mu \mathrm{mol}$ photons $\mathrm{m}^{-2} \mathrm{~s}^{-1}$ as used in earlier cotyledon screening tests (Gunasinghe et al. 2013). To avoid possible nutrient competition that potentially could influence the response to the pathogen (Burdon and Chilvers 1982), plants were fertilized weekly with the complete nutrient solution Thrive (Yates, Australia) according to the manufacturer's specification.

The phytotoxin effect and role of cercosporin in initial disease development stages on the three different host species were evaluated by comparing the damage to the host from three separate treatments, viz. as culture filtrates (i.e., cercosporin only and no pathogen hyphal fragments), hyphae in sterile distilled water (i.e., live hyphal fragments but no cercosporin from culture growth medium and any cercosporin present could only be from hyphae), and hyphae in culture growth media (i.e., cercosporin plus hyphal fragments). A mixture of mycelia from the same three $P$. capsellae isolates were used. Each isolate was subcultured on to freshly prepared MEA medium. After 2 weeks incubation at $20^{\circ} \mathrm{C}$, mycelial fragments from growing edges of each culture were aseptically transferred into separate Erlenmeyer flasks $(250 \mathrm{ml})$ containing $150 \mathrm{ml}$ of MEB. Then, cultures were
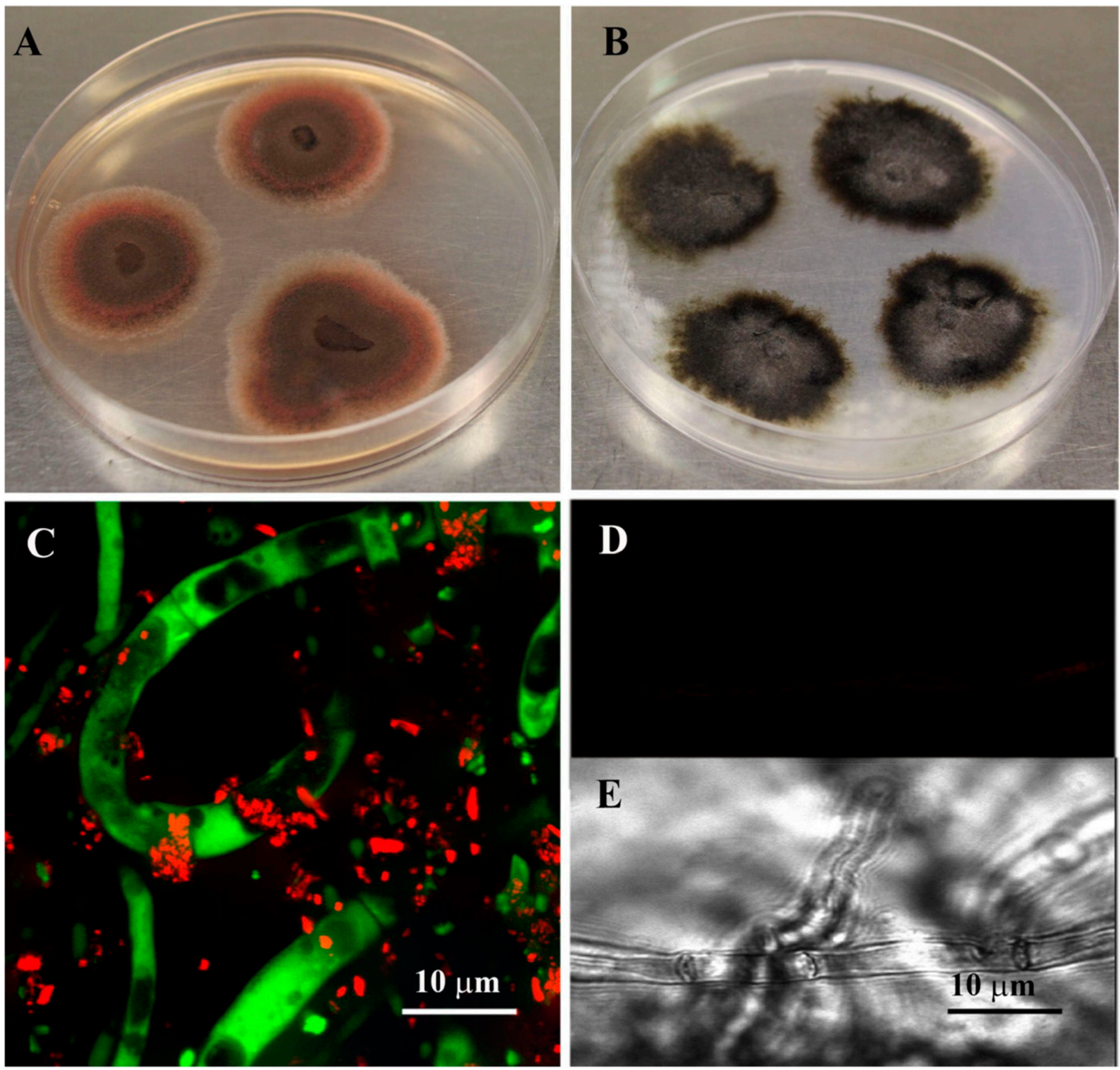

Fig. 2. With the UV excitation mode, hyphae of Pseudocercosporella capsellae isolate UWA WIra-7 produced a purple-red pigment while growing on malt extract agar (A) and emitted green fluorescence with cercosporin excreted by the fungus appearing as bright red crystals among hyphae (C). In contrast, non-cercosporin producing hyphae of isolate UWA WIn-8 (B) did not produce green fluorescence (black background only, D), despite hyphae actually being present when settings of confocal microscope were altered (E) 
incubated on a rotary platform shaker maintained at $150 \mathrm{rpm}$ at $22^{\circ} \mathrm{C}$. After 4 weeks, three treatment components were separated off, viz. culture filtrate, hyphal fragments in sterile distilled water, and hyphal fragments in culture medium, from each isolate as follows. Mycelial fragment inoculum in culture media was obtained by blending a $50 \mathrm{ml}$ aliquot of each culture showing abundant mycelial growth for $5 \mathrm{~min}$ (Stick Mixer, HB1913-C). From the remaining $100 \mathrm{ml}$, another $50 \mathrm{ml}$ fraction of each culture was filtered through two layers of cheesecloth and the mycelium collected. The hyphae collected on the cheesecloth were transferred to a sterile test tube, washed with two series of sterile distilled water, and resuspended in $50 \mathrm{ml}$ of sterile distilled water. Mycelial fragment inoculum in sterile distilled water (washed hyphae) was obtained by blending the hyphae in sterile distilled water for $5 \mathrm{~min}$ (Stick Mixer, HB1913-C). The third $50 \mathrm{ml}$ fraction of each culture was filtered through two layers of cheesecloth to collect the mycelium and the filtrate. This $50 \mathrm{ml}$ of filtrate was then refiltered through a Millipore Millex-GN $0.2 \mu \mathrm{m}$ syringe filter to obtain hyphal-free culture filtrate. The concentration of mycelial fragments for two treatments, viz. hyphal fragments in culture (original hyphae) and hyphal fragments in sterile distilled water (washed hyphae) were then adjusted to $4 \times 10^{6} \mathrm{ml}^{-1}$ using a hemocytometer counting chamber (SUPERIOR, Berlin, Germany). The procedure was repeated with each of the three isolates separately to obtain nine treatments (three per isolate).

Seven seeds of each test species were sown in $5.5 \times 5.5 \mathrm{~cm}$ pots and thinned at 10 days after sowing to three plants per pot. Twelveday-old cotyledons of each seedling were inoculated by depositing a single drop $(10 \mu \mathrm{l})$ of each of the treatments on each cotyledon lobe. Freshly prepared culture medium (MEB) and sterile distilled water were used as control comparisons. Inoculated plants were covered with clear polyethylene bags for $48 \mathrm{~h}$ to maintain high humidity in order to maximize infection (Brun and Tribodet 1991) and maintained under controlled environmental conditions described previously for 21 days. Pots were arranged in a randomized block design with nine replicates. The whole experiment was fully repeated once.

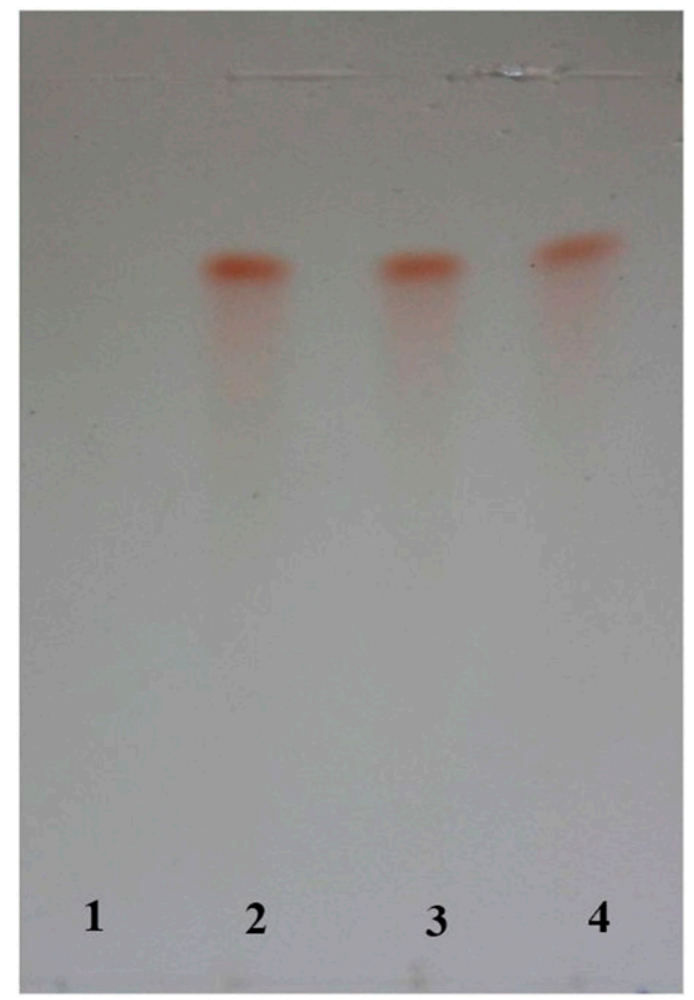

Fig. 3. Crude extract of purple-pink pigment produced by Pseudocercosporella capsellae (Isolate: UWA WIra-7) and standard cercosporin as resolved on thin layer chromatogram. Lane 1, ethyl acetate; 2, standard cercosporin; 3, pigment extract; 4 , standard cercosporin plus pigment extract.
Cotyledon reactions were recorded at two assessment times, 14 and $21 \mathrm{dpi}$, on a 0 to 9 scale developed by Eshraghi et al. (2007). Mean lesion diameters were computed for each isolate. These 0 to 9 disease scores were then converted into a percent disease index (\%DI), where:

$$
\begin{aligned}
\% \mathrm{DI}=[(\mathrm{a} \times 0)+(\mathrm{b} \times 1)+(\mathrm{c} \times 2)+(\mathrm{d} \times 3)+(\mathrm{e} \times 4) \\
+\ldots \ldots(\mathrm{j} \times 9)] /[(\mathrm{a}+\mathrm{b}+\mathrm{c}+\mathrm{d}+\mathrm{e}+\ldots \ldots \mathrm{j}) \times 9)]
\end{aligned}
$$

and where $a, b, c, d, e \ldots j$ are the number of plants with disease scores of $0,1,2,3,4, \ldots 9$, respectively. The \%DI values obtained for two time points were averaged for treatments separately in each of the two experiments. Data were analyzed separately for each experiment using two-way ANOVA with GenStat Release 14.2 (14th edition, Lawes Agricultural Trust). Significant differences between species, isolates, and treatment interactions were computed using Fisher's least significant differences (LSDs).

Extraction and analysis of cercosporin from culture filtrates. Culture filtrates $(25 \mathrm{ml})$ of each of the three isolates were transferred to separate $50 \mathrm{ml}$ centrifuge tubes. Cercosporin was extracted with $20 \mathrm{ml}$ of ethyl acetate for $8 \mathrm{~h}$ by initially adding $10 \mathrm{ml}$ for the first $4 \mathrm{~h}$, then an additional $10 \mathrm{ml}$ for an extra $4 \mathrm{~h}$, thus an $8 \mathrm{~h}$ extraction period in total. Tubes were shaken vigorously by hand for few minutes to mix ethyl acetate with the filtrate every hour of extraction. Finally, the $20 \mathrm{ml}$ of ethyl acetate extract was removed and evaporated to dryness overnight in a fume cupboard, then redissolved in $2 \mathrm{ml}$ of ethyl acetate. The cercosporin in this extract was then analyzed by HPLC as described before. The purple color of the aqueous filtrate cleared with the ethyl acetate showed this purple color by the end of the $8 \mathrm{~h}$ extraction.

\section{Results}

Pigment production. Isolates of $P$. capsellae grew in the form of "globules" in MEB under continuous rotating shaking and started to produce toxin metabolites after about 3 weeks as indicated by the change in color of the broth. The pale yellow MEB started to turn dark brown and then dark purple within 5 weeks from production of cercosporin. The color of MEB was indicative to the quantity of the pigment produced, with colors of media across the four different isolates varying from dark brown (UWA Wln-9) to dark purple (UWA Wlra-7). Under a light microscope, the morphologies of the mycelia were similar for all four isolates. Bright red crystals were ubiquitous in the medium and within the mycelium of all isolates. A variety of different individual crystal forms free-floating in the broth culture were observed (Fig. 1A to F) or on the hyphal mat (Fig. 1G to I), including conglomerates (Fig. 1G). Hyphae of $P$. capsellae isolate UWA Wlra-7 produced a purple-pink pigment while growing on MEA (Fig. 2A) and with the UV excitation mode, emitted green fluorescence with cercosporin excreted by the fungus appearing as bright red crystals among hyphae (Fig. 2C). In contrast,

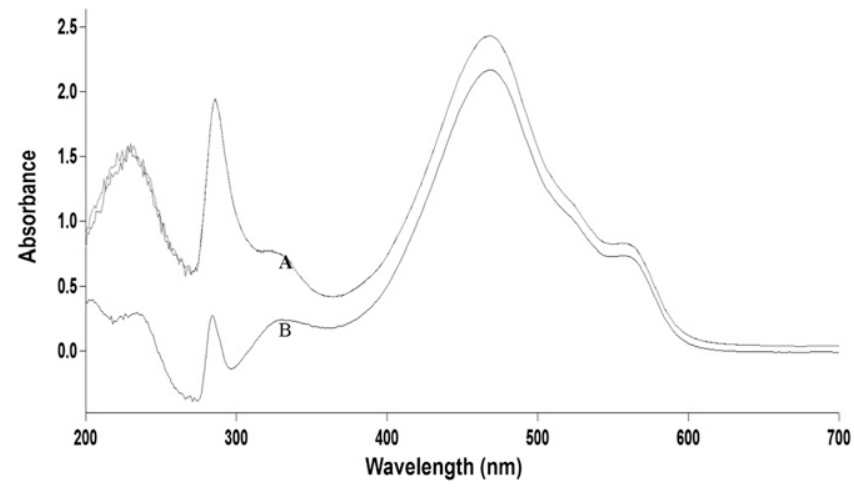

Fig. 4. Absorption spectra of crude extract of purple-pink pigment produced by Pseudocercosporella capsellae (isolate UWA WIra-7) (A) compared with the standard cercosporin in ethyl acetate (B). 
non-cercosporin producing hyphae of isolate UWA Wln-8 (Fig. 2B) did not produce green fluorescence (black background only, Fig. 2D), despite hyphae actually being present when settings of confocal microscope were altered (Fig. 2E).

On extraction into EtoAc, the colorless EtoAc layer turned bright red (provided the concentration was $\geq 45 \mu \mathrm{M}$ ) or pinkish-red (if the concentration was lower at approximately $16 \mu \mathrm{M}$ ) Small red crystals could be obtained by evaporating EtoAc.

Identification of cercosporin by TLC, UV/visible spectrum, and HPLC. Identification of cercosporin with TLC was very effective as both the cercosporin standard and the crude pigment extract had the same Rf values. On TLC plates spotted with pigment extract in EtoAc, standard cercosporin, standard cercosporin + pigment extract, and pure EtoAc, there were three similar visible spots at the same level but no visible spot for pure EtoAc (Fig. 3). These three visible spots were for standard cercosporin, pigment extract in EtoAc, and standard cercosporin + pigment extract, and $\mathrm{Rf}$ values for each visible spot were as follows: standard cercosporin $=0.853 \pm 0.02$, pigment extract from the $P$. capsellae isolate in EtoAc $=0.860 \pm 0.01$, and the combined (pigment extract in EtoAc: cercosporin standard, 1:1) = $0.856 \pm 0.03$, respectively. All three values are mean values across three identical repeat runs.

The UV/Vis absorption spectrum of the crude pigment extracts in EtoAc was identical with the spectrum for the pure cercosporin standard in the same solvent, both producing absorption maxima in the visible range at $468 \mathrm{~nm}$ (Fig. 4).

The identity of the compound was further supported by HPLC analysis of crude pigment extracts in comparison with the pure cercosporin, as the pigment extract reproduced an identical peak with the same retention time as for the pure cercosporin standard as well as a spectral match using the PDA detector; and with peak area ratios of standard vs. sample for the fluorescence and PDA detector at $470 \mathrm{~nm}$ (Figs. 5 and 6).

The reactions of dry residues of the pigment extract and the pure cercosporin standard with different chemicals are listed in Table 1. The chemical behavior of the pigment extract was highly comparable to the pure cercosporin standard and confirmed its identity as cercosporin.

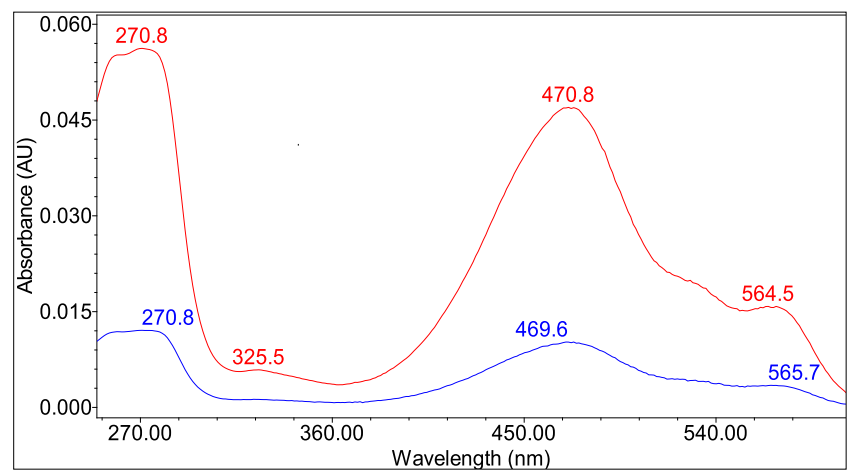

Fig. 6. Spectral image of sample peak (bottom line) compared with that of standard cercosporin (top line), obtained from HPLC analysis of pigment extract from Pseudocercosporella capsellae isolate UWA WIra-7 in ethyl acetate against standard cercosporin.
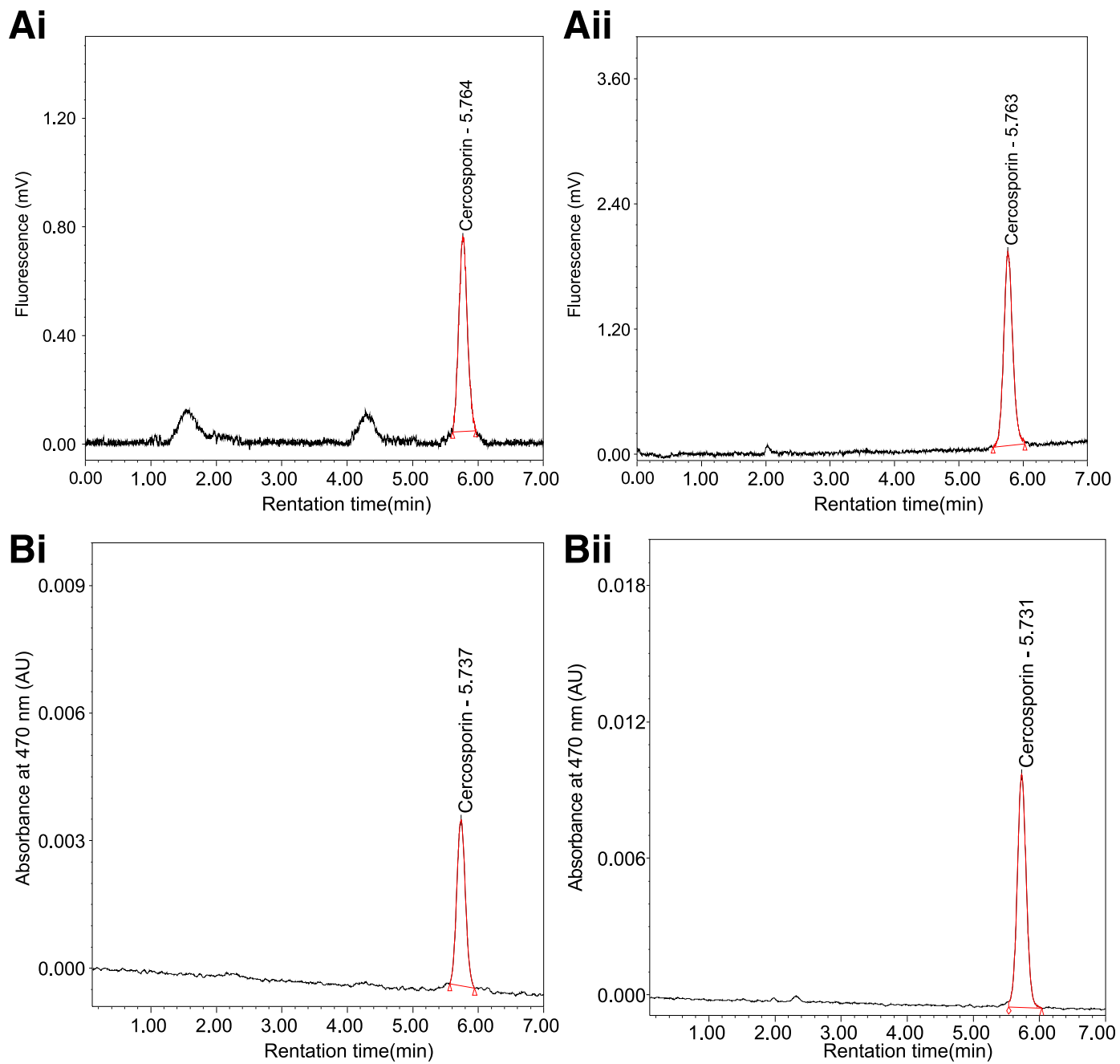

Fig. 5. Chromatograms obtained from HPLC analysis for standard cercosporin and pigment extract from Pseudocercosporella capsellae isolate UWA Wira-7 in ethyl acetate. A, Photodiode array detector output at $470 \mathrm{~nm}$, Ai standard cercosprin and Aii, pigment extract. B, Fluorescence detector output, Bi standard cercosporin and Bii pigment extract. 
Extraction of cercosporin from developing white leaf spot lesions. Cercosporin was detected in ethyl acetate extracts of disease lesions of both species, B. juncea and B. napus, by HPLC, but not from control samples (Table 2).

Phytotoxicity and role of cercosporin in disease initiation in three different host species. Results showed significant differences $(P<0.001)$ in lesion development on cotyledons of the three hosts (Table 3 ) in production of cercosporin across the three isolates and in terms of disease severity levels in different treatments (Table 3).

The isolate UWA Wlra-7 produced significantly $(P<0.001)$ greater amounts of cercosporin than the other two isolates, and did so consistently across two experiments. Cercosporin production in the other two isolates was much less and not consistent (Table 3). Therefore, the amount of cercosporin produced during a specific growth period varied depending upon the isolate. A significantly $(P<0.001)$ greater quantity of cercosporin was consistently produced by UWA Wlra-7 (105.4, 106.02) (Table 3). Production of cercosporin became apparent by the color change of the growth medium. Presence of ample cercosporin in culture medium changed its color from pale cream to dark purple. Coloration from the cercosporin was particularly noticeable in culture filtrate from UWA Wlra-7 that had a high amount of cercosporin (Fig. 7).

Culture filtrates containing cercosporin were toxic to all three host plant species, but with different degrees of sensitivity (Table 3). Cotyledon lesions were induced by the hyphal-free culture filtrate rich in cercosporin on B. juncea Rohini (Fig. 8A), B. napus Trilogy (Fig. 8D), and $R$. raphanistrum (Fig. 5G). Lesions also developed from washed live hyphae on cotyledons of B. juncea Rohini (Fig. 8B), B. napus Trilogy (Fig. 8E), and $R$. raphanistrum (Fig. 8H). Cotyledon lesions were also induced by unwashed "original" hyphae on three host species, viz. B. juncea Rohini (Fig. 8C), B. napus Trilogy (Fig. 8F), and on R. raphanistrum (Fig. 8I). For highly sensitive $B$. juncea Rohini, cercosporin induced comparatively large, white lesions on cotyledons resembling mature lesions developed by the pathogen itself on field plants (Fig. 8A). In contrast, only water-soaked areas were observed on less sensitive cotyledons of $R$. raphanistrum (Fig. 8G). Cotyledons of all three host species remained completely healthy when inoculated with either fresh culture filtrate or with distilled water controls. The leaf lesions caused by the culture filtrate from UWA Wlra-7, an isolate producing abundant cercosporin, were significantly different $(P<0.001)$ across the three host species, viz. lesions more conspicuous in $B$. juncea Rohini as indicated by higher $\%$ mean lesion sizes ( 25.07 and 20.01), intermediate on B. napus Trilogy (9.21 and 9.62), and least on $R$. raphanistrum cotyledons (5.89 and 5.35) across both experiments (Table 3 ). Culture filtrates from other two isolates (UWA Wln-9 and UWA Wlj-3) with less cercosporin also demonstrated toxic effects on all three host species, though any comparative trends between hosts were not as clear as with cercosporin-rich culture filtrate from UWA Wlra-7. However, on the cotyledons of $B$. juncea, there was a strong positive correlation $\left(R^{2}=0.54, P<0.001\right)$ evident between the concentration of cercosporin with the size of lesion induced.
Generally $P$. capsellae was more effective in producing lesions on cotyledons when applied as unwashed "original" hyphae. Again this difference was obvious in both experiments with the high cercosporin producing isolate UWA Wlra-7, as \%DI in cotyledons in this instance was markedly higher when inoculated as original hyphae without washing as compared with lesion development in cotyledons inoculated with washed hyphae. For instance, when treated with original hyphae and washed hyphae of UWA Wlra-7, B. juncea Rohini showed significantly $(P<0.001)$ greater disease development than when treated with washed hyphae in experiment $1(\% \mathrm{DI}=30.94$, $16.54)$ and experiment $2(\% \mathrm{DI}=31.1,14.25)$, respectively (Table 3 , Fig. 8B and C).

All three isolates of $P$. capsellae were more virulent against $B$. juncea Rohini, as represented by high \%DI values, compared with the other two host species. Significant $(P<0.001)$ difference was observed in both experiments with treatment with UWA Wlra-7, which was highly virulent on $B$. juncea Rohine, intermediate on $R$. raphanistrum, and least virulent on B. napus Trilogy (Table 3, Fig. 8C, F, and I).

\section{Discussion}

This is the first study to show that the purple-pink pigment produced by $P$. capsellae is cercosporin, demonstrated by extracting and characterizing it as follows. First, qualitative chemical tests and quantitative analysis conducted in comparison with standard cercosporin from C. kikuchii (Callahan et al. 1999) confirmed identical results to our study with $P$. capsellae. Second, the identical nature of the pigment extract with standard cercosporin was obtained by TLC and absorption spectra in EtoAc, where thin layer chromatography of both gave similar Rf values and the absorption spectrum of pigment extract was comparable with the cercosporin standard, with both having peak absorption maxima at $468 \mathrm{~nm}$. While this value was slightly different to the published value for the peak absorption maxima for cercosporin in EtoAc at $473 \mathrm{~nm}$ (Tessmann et al. 2008), the absorption maxima were identical for both standard cercosporin and crude pigment extract in our study. In addition, we believe that this is the first study to demonstrate that $P$. capsellae produces cercosporin in

Table 2. Cercosporin ( $\mathrm{mg} \mathrm{g}^{-1}$ of dry weight of diseased tissue) determined by HPLC in ethyl acetate extract of diseased or healthy (control) tissue samples from Brassica juncea and B. napus spray inoculated with a Pseudocercosporella capsellae mycelial suspension

\begin{tabular}{llc}
\hline Host species & \multicolumn{1}{c}{ Sample } & $\begin{array}{c}\text { Cercosporin content }\left(\mathbf{m g ~ g}^{\mathbf{- 1}}\right) \\
\text { dry weight of diseased leaf area }\end{array}$ \\
\hline B. juncea & Disease lesions 1 & 0.79 \\
& Disease lesions 2 & 0.55 \\
& Control & $\mathrm{ND}^{\mathrm{a}}$ \\
B. napus & Disease lesions 1 & 0.66 \\
& Disease lesions 2 & 0.55 \\
& Control & $\mathrm{ND}$ \\
\hline
\end{tabular}

a $\mathrm{ND}=$ not detected

Table 1. Color reactions of a pure cercosporin standard and the crude pigment extracted from hyphae of a 3-week-old culture of Pseudocercosporella capsellae in malt extract broth using standard reagents and procedures as used in the studies listed (see references below)

\begin{tabular}{llll}
\hline Reagent & $\begin{array}{c}\text { Color of the } \\
\text { pigment extract }\end{array}$ & $\begin{array}{c}\text { Color of the } \\
\text { standard cercosporin }\end{array}$ & Reference \\
\hline $1 \mathrm{M} \mathrm{KOH}$ & Green & Green & Balis and Payne 1971; Guchu and Cole 1994; Jenns et al. 1989 \\
$1 \mathrm{M} \mathrm{HCl}$ & Red & Red & Balis and Payne 1971; Fore et al. 1988; Guchu and Cole 1994 \\
$1 \mathrm{M} \mathrm{NaOH}$ & Green & Green & Balis and Payne 1971 \\
$\mathrm{Concentrated} \mathrm{H}_{2} \mathrm{SO}_{4}$ & Purple & Purple & Balis and Payne 1971; Guchu and Cole 1994; \\
& & Kuyama and Tamura 1957 \\
$\mathrm{H}_{2} \mathrm{O}$ & Insoluble & Insoluble & Balis and Payne 1971; Guchu and Cole 1994 \\
$\mathrm{Concentrated} \mathrm{H}_{2} \mathrm{SO}_{4}+\mathrm{H}_{2} \mathrm{O}$ & Bluish purple & Bluish purple & Balis and Payne 1971; Guchu and Cole 1994; \\
& precipitate & precipitate & Kuyama and Tamura 1957 \\
Acetone & Bright red & Bright red & Fajola 1978 \\
Acidic + neutral conditions $(<7.7 \mathrm{pH})$ & Red & Red & Fore et al. 1988 \\
Basic conditions $(>7.7 \mathrm{pH})$ & Green & Green & Fore et al. 1988; Kuyama and Tamura 1957 \\
\hline
\end{tabular}


Table 3. Percentage disease index (\%DI) and the content of cercosporin $(\mu \mathrm{M})$ in cell-free culture filtrates of three host species $($ Brassica juncea, B. napus, and Raphanus raphanistrum) grown under controlled environment room at $15^{\circ} \mathrm{C}, 12 \mathrm{~h}$ photoperiod, and a light intensity of $580 \mu \mathrm{mol}$ photons $\mathrm{m}^{-2} \mathrm{~s}^{-1}$, treated with three treatments: culture filtrate (without live hyphae), washed hyphae (without culture medium), and original hyphae in the culture medium with three isolates of Pseudocercosporella capsellae (UWA Wlra-7,UWA Wlj-3, and UWA Wln-9) ${ }^{\mathrm{a}}$

\begin{tabular}{|c|c|c|c|c|c|}
\hline \multirow[b]{2}{*}{ Host } & \multirow[b]{2}{*}{ Isolate } & \multicolumn{2}{|c|}{ Filtrate } & \multirow{2}{*}{$\frac{\text { Washed hyphae }}{\text { Mean \%DI }}$} & \multirow{2}{*}{$\frac{\text { Original (unwashed hyphae) }}{\text { Mean \%DI }}$} \\
\hline & & Cercosporin con. $\mu \mathrm{M}$ & Mean \%DI & & \\
\hline \multicolumn{6}{|l|}{ Experiment 1} \\
\hline B. juncea & WLn-9 & $\mathrm{ND}^{\mathrm{b}}$ & 0.87 & 3.88 & 5.32 \\
\hline B. juncea & WLj-3 & 1 & 2.85 & 2.88 & 5.84 \\
\hline B. juncea & WLra-7 & 105.4 & 25.07 & 16.54 & 30.94 \\
\hline B. napus & WLn-9 & ND & 0.67 & 2.39 & 4.17 \\
\hline B. napus & WLj-3 & 1 & 0.57 & 1.57 & 4.06 \\
\hline B. napus & WLra-7 & 105.4 & 9.21 & 10.96 & 12.19 \\
\hline R. raphanistrum & WLn-9 & ND & 0 & 2.31 & 1.83 \\
\hline R. raphanistrum & WLj-3 & 1 & 0.28 & 1.34 & 2.37 \\
\hline R. raphanistrum & WLra-7 & 105.4 & 5.89 & 9.49 & 14.04 \\
\hline \multicolumn{6}{|l|}{ Experiment 2} \\
\hline B. juncea & WLn-9 & 1.2 & 3.11 & 2.11 & 6.89 \\
\hline B. juncea & WLj-3 & ND & 0.98 & 4.71 & 4.18 \\
\hline B. juncea & WLra-7 & 106.2 & 20.01 & 14.25 & 31.1 \\
\hline B. napus & WLn-9 & 1.2 & 1.85 & 2.70 & 5.50 \\
\hline B. napus & WLj-3 & ND & 0.67 & 2.67 & 3.40 \\
\hline B. napus & WLra-7 & 106.2 & 9.62 & 10.33 & 16.74 \\
\hline R. raphanistrum & WLn-9 & 1.2 & 1.59 & 1.57 & 4.06 \\
\hline R. raphanistrum & WLj-3 & ND & 0.77 & 1.36 & 2.01 \\
\hline R. raphanistrum & WLra-7 & 106.2 & 5.35 & 7.05 & 12.45 \\
\hline
\end{tabular}

${ }^{a}$ Significance of host $(P \leq 0.001)$; LSD $P \leq 0.05=\operatorname{Exp} 1,1.689 ;$ Exp2, 2.73. Significance of isolate $(P \leq 0.001) ;$ LSD $P \leq 0.05=\operatorname{Exp} 1,1.689 ;$ Exp2, 2.73.

Significance of treatment $(P \leq 0.001)$; LSD $P \leq 0.05=$ Exp1, 1.689; Exp2, 2.73. Significance of host $\times$ isolate $(P \leq 0.001)$; LSD $P \leq 0.05=$ Exp1, 2.926; Exp2, 4.73. Significance of host $\times$ treatment $(P \leq 0.001)$; LSD $P \leq 0.05=\operatorname{Exp2}, 4.73$. Significance of isolate $\times$ treatment $(P \leq 0.001) ;$ LSD $P \leq 0.05=$ Exp1, 2.926.

${ }^{\mathrm{b}} \mathrm{ND}=$ not detected (minimum detection: $\left.0.05 \mu \mathrm{M}\right)$.

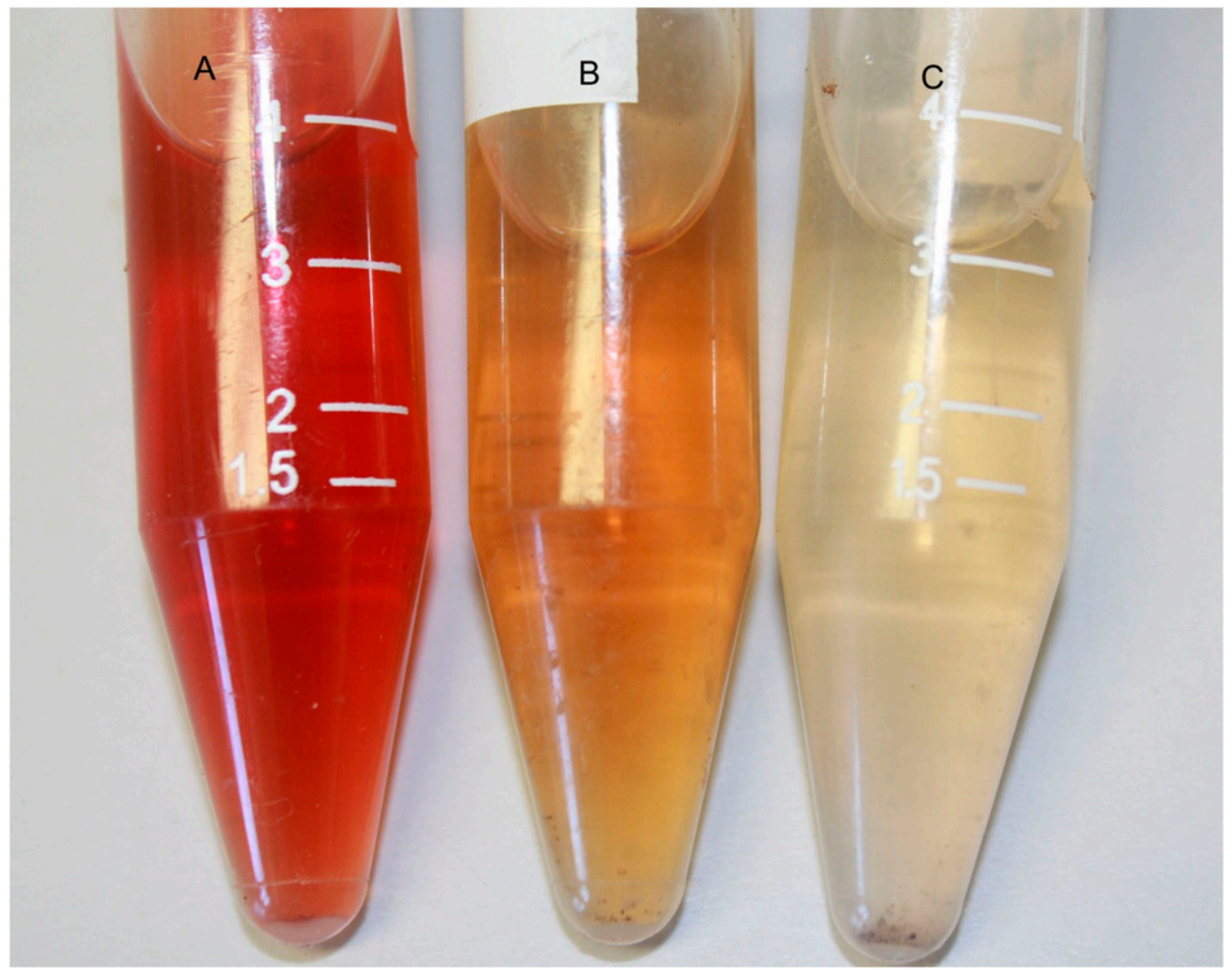

Fig. 7. Color differences of the culture filtrates obtained by three isolates of Pseudocercosporella capsellae for experiment 1. A, Culture filtrate obtained from UWA Wira-7, with high amount of cercosporin. B, Culture filtrate obtained from UWA Wli-3. C, Culture filtrate obtained from UWA WIn-9 as indicated by its color and HPLC analysis (Table 3). 
liquid media. Finally, this study highlights an important role of cercosporin as a pathogenicity factor in white leaf spot disease on Brassicaceae as evidenced by the production of cercosporin in vivo, the ability of cercosporin-rich culture filtrate to reproduce white leaf spot lesions on host plants, and by the enhanced virulence of $P$. capsellae in the presence of cercosporin.

Production of cercosporin is common among the pathogenic fungi belonging to genus Cercospora. They are a highly successful and widespread group of pathogens that cause damaging leaf spot and blight diseases to diverse crop species including corn, sugar beet, rice, banana, coffee, soybean, and several other ornamental and vegetable species. The ability to produce cercosporin is believed to be one of the factors for their successful pathogenesis over different crop species (Daub and Ehrenshaft 2000). Our study reports production of cercosporin by a species other than Cercospora sp. However, it is not surprising as these to genera likely to have close phylogenetic relationships. Both genera, Pseudocercosporella and Cercospora, are in the family Mycosphaerellaceae. A phylogenetic study based on 28S nuclear ribosomal RNA gene by Crous et al. (2013) demonstrated Pseudocercosporella resides in a large clade along with Phloeospora, Miuraea, Cercospora, and Septoria within the Mycosphaerellaceae, suggesting close phylogenetic relationships between these four genera. Further, recent studies based on multigene phylogenetic data have indicated that Pseudocercosporella is a polyphyletic taxon comprising a genetically heterogeneous assemblage of fungi (Crous et al. 2013; Frank et al. 2010) with some species residing in the Cercospora clade (Bakhshi et al. 2015).
Cercosporin produced larger lesions on B. juncea and B. napus genotypes and these two species were more susceptible to $P$. capsellae than $R$. raphanistrum (wild radish) in earlier studies (Gunasinghe et al. 2013, 2016), where only water-soaked areas were more often observed. Lesions induced on susceptible host species by the phytotoxic culture filtrate containing cercosporin were white and indicative of mature white leaf spot lesions on Brassicaceae as caused when the pathogen is present (Gunasinghe et al. 2013). It was evident that the sensitivity to cercosporin depended on two factors, viz. the concentration of the toxin and the host species. For example, filtrate with a high content of cercosporin on comparatively resistant seedlings ( $R$. raphanistrum) or culture filtrate with low content of cercosporin (e.g., culture filtrate from UWA Wlj-3) on the highly sensitive and susceptible B. juncea Rohini were only able to induce water soaked areas on the cotyledon surface. While cercosporin is reported as a universal phytotoxin, it was evident that sensitivity to this toxin depends on the host susceptibility/resistance (Daub and Ehrenshaft 2000) and/or the toxin content (Batchvarova et al. 1992). Producing water-soaked areas on leaves, even if not reported before for this phytotoxin, is a type of damage known to be induced by pathogen toxic metabolites (Amusa 2006). However, when applied to leaves, cercosporin causes necrotic or chlorotic areas that subsequently became gray brown "hollows" on other hosts (Balis and Payne 1971; Fajola 1978; Guchu and Cole 1994). Similarly, historical studies found that cercosporin sensitivity depends on host species. For instance, Fajola (1978) showed that the minimum dose of cercosporin from Cercospora spp. needed to induce symptoms on different host plants varied depending on the different sensitivity
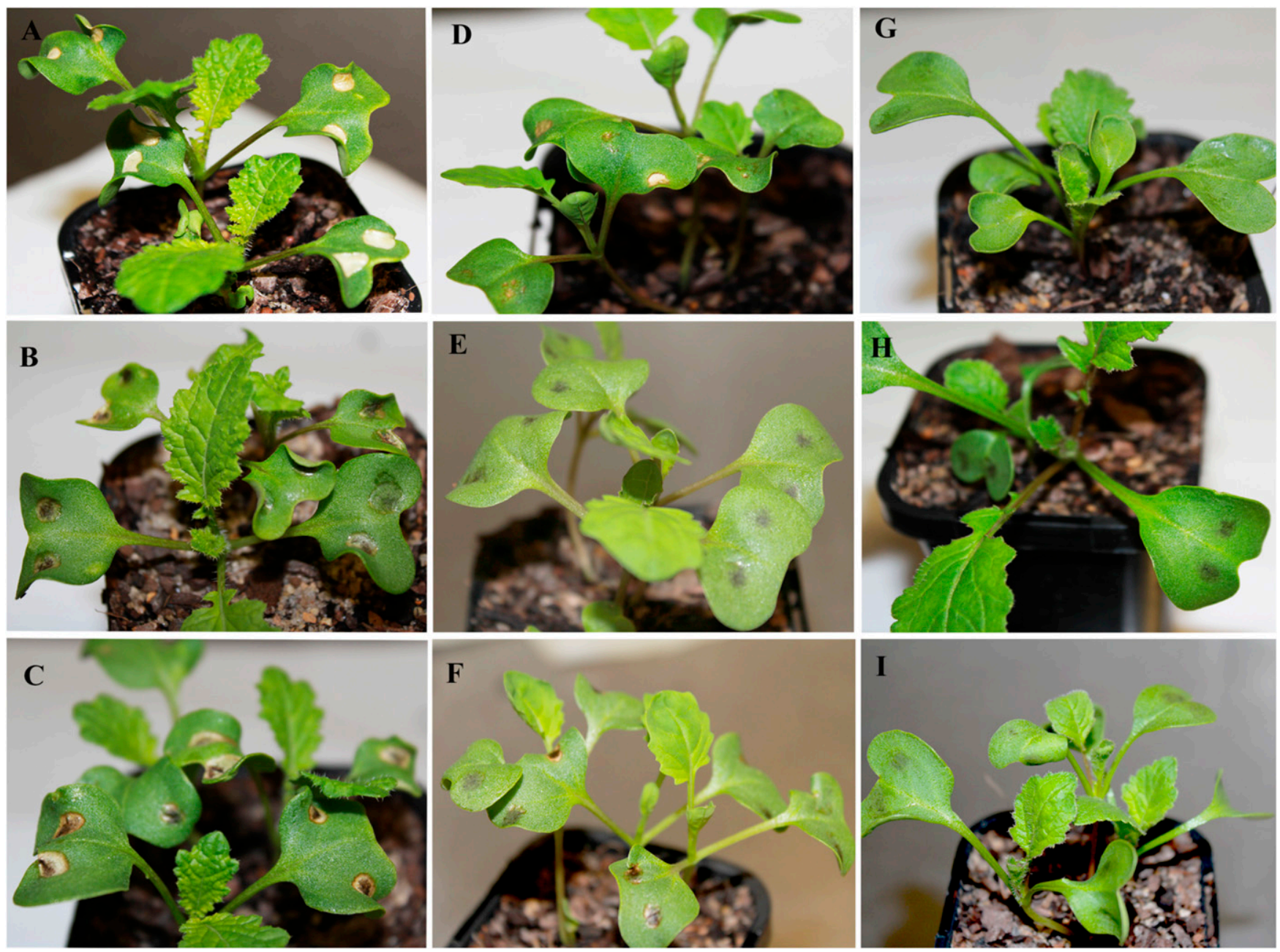

Fig. 8. 20-day-old Brassica seedlings inoculated with culture filtrates or live hyphae of Pseudocercosporella capsellae (UWA Wira-7) grown under controlled environment room at $15^{\circ} \mathrm{C}, 12 \mathrm{~h}$ photoperiod, and a light intensity of $580 \mu \mathrm{mol}$ photons $\mathrm{m}^{-2} \mathrm{~s}^{-1}$. Cotyledon lesions induced by hyphal-free culture filtrate rich in cercosporin on $\mathrm{A}, \mathrm{Brassica}$ juncea Rohini, D, B. napus Trilogy, and G, Raphanus raphanistrum. Lesions developed by washed live hyphae on cotyledons of B, B. juncea Rohini, E, B. napus Trilogy, and $\mathbf{H}$, $R$. raphanistrum. Cotyledon lesions were also induced by original hyphae on three host species: C, B. juncea Rohini, $\mathrm{F}, B$. napus Trilogy, and I, on $R$. raphanistrum. 
levels of plant hosts to cercosporin. For example, Fajola (1978) found that with cassava (Manihot esculenta), symptoms were not observed even with the highest treated dose of $100 \mu \mathrm{g} \mathrm{ml}^{-1}$. In contrast, while chlorosis developed in castor oil plants (Ricinus communis) with the same dose, only $10 \mu \mathrm{g} \mathrm{ml}^{-1}$ of cercosporin was needed to induce visible symptoms in tobacco (Nicotiana tabacum). Batchvarova et al. (1992) found that resistance to pure cercosporin paralleled the degree of resistance shown by rice cultivars to Cercospora oryzae and that highly susceptible cultivars displayed particularly high affinity to damage from cercosporin in susceptible cells. Similarly, there was a positive correlation between resistance to leaf spot disease and the sensitivity of five different greenhouse grown sugar beet (Beta vulgaris) cultivars to cercosporin (Balis and Payne 1971). This being so, cercosporin likely offers an opportunity to provide a rapid indication of the relative resistances/susceptibilities of Brassicaceae genotypes in the same way as this has already been undertaken with screening of germplasm of cassava cultivars for resistance to anthracnose using toxic metabolites of Colletotrichum species (Amusa 1998, 2001). Further, application of a screening technique involving cercosporin is not only relevant because pure cercosporin can reproduce similar lesions stimulated by the pathogen itself on corresponding host species (Balis and Payne 1971; Fajola 1978; Guchu and Cole 1994; Venkataramani 1967), but cercosporin also produces similar initial changes at the cellular level (Steinkamp et al. 1981).

One of the few requirements needed to ensure symptoms from application of cercosporin is the light dependency for cercosporin to be toxic (Upchurch et al. 1991). Cercosporin has long been identified as a photosensitizer (i.e., molecules that absorb light energy then converted into a long-lived electronically excited triplet state that produces activated oxygen species) (Daub and Ehrenshaft 2000; Hartman et al. 1988; Leisman and Daub 1992). Hence, light is critical for toxic action, the majority of which is attributed to production of singlet oxygen $\left({ }^{1} \mathrm{O}_{2}\right)$ and superoxide $\left(\mathrm{O}_{2}^{-}\right)$(Daub and Ehrenshaft 2000; Hartman et al. 1988). Macri and Vianello (1979) demonstrated the light dependency for cercosporin in affecting plant tissues. Cell membrane damage by lipid peroxidation has been proposed as the mode of action of cercosporin (Cavallini et al. 1979) and is associated with nutrient leakage and DNA impairment (Daub 1982; Daub and Briggs 1983). For example, ultrastructural studies by Steinkamp et al. (1981) highlighted membrane damage to sugar beet (B. vulgaris) cells by cercosporin-producing Cercospora beticola during the early stages of disease development. Further, in toxintreated plant tissues, necrosis or chlorosis from Cercospora spp. occurs across castor oil plant (R. communis), soybean (Glycine max), tobacco (N. tabacum), common bean (Phaseolus vulgaris), and cowpea (Vigna unguiculata) (Fajola 1978), as do necrotic lesions on sugar beet leaves (Balis and Payne 1971).

The results suggest that cercosporin is a pathogenicity factor during pathogenesis of $P$. capsellae. Detection of cercosporin from white leaf spot lesions and the positive correlation between the level of cercosporin production and the virulence of the isolates strongly support this conclusion. In the current study, the virulence of the isolates was strongly correlated with the level of cercosporin production. High virulence of UWA Wlra-7, for example, is likely due to elevated production of cercosporin. A recent study by Gunasinghe et al. (2016) also highlighted the strong positive correlation between pigment production by $P$. capsellae on agar with virulence on Brassicaceae. Further, in the current study, that there is more severe disease development following inoculation with hyphae grown in culture media as compared with washed hyphae is indicative of a role of cercosporin in disease initiation and development. This is particularly so as cercosporin has long been suggested as a pathogenicity factor in other studies across many Cercospora diseases (Daub 1982; Fajola 1978; Upchurch et al. 1991). To confirm the role of cercosporin in disease development, Upchurch et al. (1991) demonstrated the lack of pathogenicity in UV-induced mutants. Cercosporin has been successfully extracted from diseased leaves (Fajola 1978; Venkataramani 1967), further suggesting it plays an important role in lesion development. Further, when isolating from white leaf spot lesions on canola in an Australia-wide foliar disease survey in 2015, purple-pink coloration of water agar was observed directly around plated lesions even before active growth of $P$. capsellae was evident (M. J. Barbetti, unpublished). In the same way as cercosporin could be used to determine relative host resistances/susceptibilities, relative cercosporin production by $P$. capsellae isolates could be utilized to define the relative virulences of such isolates. Host-pathogen interactions involving Cercospora zeae-maydis causing gray leaf spot of maize (Shim and Dunkle 2003) and C. kikuchii causing purple seed stain disease of soybean (Callahan et al. 1999) are in large part determined by the production of cercosporin. Hence, cercosporin could be utilized to determine the virulence of an isolate by relative production of cercosporin (as a pathogenicity factor) and susceptibility of a host plant by the sensitivity of the host plant to cercosporin (as a host resistance/susceptibility factor).

The three $P$. capsellae isolates used in the current study were identified as cercosporin producers on MEA (Gunasinghe et al. 2016). However, two isolates, UWA Wlj-3 and UWA Wln-9, did not produce detectable levels of cercosporin in one out of two experiments (and only a low level of cercosporin in the other experiment). It is evident that the quantity of cercosporin produced by different isolates can vary greatly. This is not surprising as the level of cercosporin produced is known to vary among species (Fajola 1978; Jenns et al. 1989) and across isolates of the same species (Tessmann et al. 2008; Upchurch et al. 1991). Its production is dependent upon several factors, as it is a composite process involving complex regulatory cascades, where there are numerous environmental and physiological factors that influence cercosporin production (You et al. 2008). In the current study, hyphae of $P$. capsellae emitted a green fluorescence under confocal microscopy with numerous red crystals in the immediate vicinity. Cercosporin-producing hyphae emitting such green fluorescence is a known indication of cercosporin in a chemically reduced state inside hyphae (Chung et al. 2002; Daub et al. 2005), important as this provides protection of the Cercospora spp. from their own cercosporin production and toxicity (Daub et al. 2000).

\section{Acknowledgments}

The first author is grateful for the financial assistance of an International SIRF Scholarship funded jointly by the Australian Government and The University of Western Australia. John Murphy at the Centre for Microscopy and Characterisation is gratefully acknowledged for excellent assistance with the confocal microscopy component of this study. We thank the School of Plant Biology, The University of Western Australia, for funding this work.

\section{Literature Cited}

Amusa, N. 1998. Evaluation of cassava clones for resistance to anthracnose disease using phytotoxic metabolites of Colletotrichum gloeosporioides f. sp. manihotis and its correlation with field disease reactions. Trop. Agric. Res 1:116-120.

Amusa, N. 2001. Screening of cassava and yam cultivars for resistance to anthracnose using toxic metabolites of Colletotrichum species. Mycopathologia 150:137-142.

Amusa, N. 2006. Microbially produced phytotoxins and plant disease management. Afr. J. Biotechnol. 5:405-414.

Assante, G., Locci, R., Camarda, L., Merlini, L., and Nasini, G. 1977. Screening of the genus Cercospora for secondary metabolites. Phytochemistry 16:243-247.

Bakhshi, M., Arzanlou, M., Babai-Ahari, A., Groenewald, J. Z., and Crous, P. 2015. Is morphology in Cercospora a reliable reflection of generic affinity? Phytotaxa 213:22-34.

Balis, C., and Payne, M. 1971. Triglycerides and cercosporin from Cercospora beticola: fungal growth and cercosporin production. Phytopathology 61:1477-1484.

Barbetti, M. J., and Khangura, R. 2000. Fungal diseases of canola in Western Australia. Bulletin 4406. Agriculture Western Australia, Perth, WA.

Barbetti, M. J., and Sivasithamparam, K. 1981. Pseudocercosporella capsellae and Myrothecium verrucaria on rapeseed in Western Australia. Australas. Plant Pathol. 10:43-44.

Batchvarova, R., Reddy, V., and Bennett, J. 1992. Cellular resistance in rice to cercosporin, a toxin of Cercospora. Phytopathology 82:642-646.

Blaney, C. L., Van Dyke, C. G., and Grand, L. F. 1988. Cercospora caricis from Cyperus esculentus (yellow nutsedge): morphology and cercosporin production. Mycologia 80:418-421.

Brun, H., and Tribodet, M. 1991. A method for estimate the level of resistance in oilseed rape to Pseudocercosporella capsellae. Bull. OILB SROP 14: 64-66.

Burdon, J. J., and Chilvers, G. A. 1982. Host density as a factor in plant disease ecology. Annu. Rev. Phytopathol. 20:143-166.

Callahan, T., Rose, M., Meade, M., Ehrenshaft, M., and Upchurch, R. 1999. CFP, the putative cercosporin transporter of Cercospora kikuchii, is required for wild 
type cercosporin production, resistance, and virulence on soybean. Mol. PlantMicrobe Interact. 12:901-910.

Campbell, R., and Greathead, A. S. 1978. Pseudocercosporella white spot of crucifers in California. Plant Dis. Rep. 62:1066-1068.

Cavallini, L., Bindoli, A., Macri, F., and Vianello, A. 1979. Lipid peroxidation induced by cercosporin as a possible determinant of its toxicity. Chem. Biol. Interact. 28:139-146.

Cerkauskas, R. F., Stobbs, L. W., Lowery, D. T., Van Driel, L., Liu, W., and VanSchagen, J. 1998. Diseases, pests, and abiotic problems associated with oriental cruciferous vegetables in southern Ontario in 1993-1994. Can. J. Plant Pathol. 20:87-94.

Choquer, M., Lee, M. H., Bau, H. J., and Chung, K. R. 2007. Deletion of a MFS transporter-like gene in Cercospora nicotianae reduces cercosporin toxin accumulation and fungal virulence. FEBS Lett. 581:489-494.

Chung, K., Ehrenshaft, M., and Daub, M. 2002. Functional expression and cellular localization of cercosporin-resistance proteins fused with the GFP in Cercospora nicotianae. Curr. Genet. 41:159-167.

Crossan, D. F. 1954. Cercosporella leafspot of crucifers. North Carolina Agricultural Experiment Station Technical Bulletin 109:23.

Crous, P., Braun, U., Hunter, G. C., Wingfield, M., Verkley, G., Shin, H.-D., Nakashima, C., and Groenewald, J. 2013. Phylogenetic lineages in Pseudocercospora. Stud. Mycol. 75:37-114.

Daub, M. E. 1982. Peroxidation of tobacco membrane lipids by the photosensitizing toxin, cercosporin. Plant Physiol. 69:1361-1364.

Daub, M. E. 1987. The fungal photosensitizer cercosporin and its role in plant disease. Pages 271-280 in: Light-Activated Pesticides. J. R. Heitz and K. R. Downum, eds. American Chemical Society, Washington, DC.

Daub, M. E., and Briggs, S. P. 1983. Changes in tobacco cell membrane composition and structure caused by cercosporin. Plant Physiol. 71: $763-766$.

Daub, M. E., and Ehrenshaft, M. 2000. The photoactivated Cercospora toxin cercosporin: contributions to plant disease and fundamental biology. Annu. Rev. Phytopathol. 38: 461-490.

Daub, M. E., Herrero, S., and Chung, K.-R. 2005. Photoactivated perylenequinone toxins in fungal pathogenesis of plants. FEMS Microbiol. Lett. 252:197-206.

Daub, M. E., Leisman, G. B., Clark, R. A., and Bowden, E. F. 1992. Reductive detoxification as a mechanism of fungal resistance to singlet oxygengenerating photosensitizers. Proc. Natl. Acad. Sci. 89:9588-9592.

Daub, M. E., Li, M., Bilski, P., and Chignell, C. F. 2000. Dihydrocercosporin singlet oxygen production and subcellular localization: a possible defense against cercosporin phototoxicity in Cercospora. Photochem. Photobiol. 71:135-140.

Dobrowolski, D. C., and Foote, C. S. 1983. Cercosporin, a singlet oxygen generator. Angew. Chem. Int. Ed. Engl. 22:720-721.

Eshraghi, L., Barbetti, M. J., Li, H., Danehloueipour, N., and Sivasithamparam, K. 2007. Resistance in oilseed rape (Brassica napus) and Indian mustard (Brassica juncea) to a mixture of Pseudocercosporella capsellae isolates from Western Australia. Field Crops Res. 101:37-43.

Eshraghi, L., You, M. P., and Barbetti, M. J. 2005. First report of white leaf spot caused by Pseudocercosporella capsellae on Brassica juncea in Australia. Plant Dis. 89:1131.

Fajola, A. 1978. Cercosporin, a phytotoxin from Cercospora spp. Physiol. Plant Pathol. 13:157-164.

Fore, S., Daub, M., and Beute, M. 1988. Phytotoxic substances produced by some isolates of Cercospora arachidicola are not cercosporin. Phytopathology 78: 1082-1086.

Frank, J., Crous, P., Groenewald, J., Oertel, B., Hyde, K., Phengsintham, P., and Schroers, H.-J. 2010. Microcyclospora and Microcyclosporella: novel genera accommodating epiphytic fungi causing sooty blotch on apple. Persoonia Mol. Phyl. Evol. Fungi 24:93-105.

Guchu, H. S., and Cole, D. L. 1994. The toxicity of phytotoxins from Cercospora arachidicola and cercosporin from Cercospora species to tobacco, Swiss chard and groundnut plants. Mycol. Res. 98:1245-1252.

Gunasinghe, N., You, M. P., Banga, S. S., and Barbetti, M. J. 2013. High level resistance to Pseudocercosporella capsellae offers new opportunities to deploy host resistance to effectively manage white leaf spot disease across major cruciferous crops. Eur. J. Plant Pathol. 138:873-890.

Gunasinghe, N., You, M. P., and Barbetti, M. J. 2016. Phenotypic and phylogenetic studies associated with the crucifer white leaf spot pathogen, Pseudocercosporella capsellae, in Western Australia. Plant Pathol. 65:205-217.

Hamblin, P., Kirkegard, J., and Sprague, S. 2004. Blackleg and Sclerotinia management research in canola, Research Update for Advisers - Northern/Southern Region. The Grains Research and Development Corporation, Canberra, Australia.

Hartman, P. E., Dixon, W. J., Dahl, T. A., and Daub, M. E. 1988. Multiple modes of photodynamic action by cercosporin. Photochem. Photobiol. 47: 699-703.
Henry, F. D., and Steve, M. 2014. White leaf spot of canola, ExtensionAUS. http:// www.extensionaus.com.au/white-leaf-spot/

Inman, A. J. 1992. The biology and epidomiology of white leaf spot (Pseudocercosporella capsellae) on oilseed rape. Department of Plant Pathology, The University of London.

Jenns, A. E., Daub, M. E., and Upchurch, R. G. 1989. Regulation of cercosporin accumulation in culture by medium and temperature manipulation. Phytopathology 79:213.

Kuyama, S. 1962. Cercosporin. A pigment of Cercosporina kikuchii Matsumoto et Tomoyasu. III. The nature of the aromatic ring of cercosporin. J. Org. Chem. 27: 939-944.

Kuyama, S., and Tamura, T. 1957. Cercosporin. A pigment of Cercosporina kikuchii Matsumoto et Tomoyasu. I. Cultivation of fungus, isolation and purification of pigment. J. Am. Chem. Soc. 79:5725-5726.

Leisman, G. B., and Daub, M. E. 1992. Singlet oxygen yields, optical properties, and phototoxicity of reduced derivatives of the photosensitizer cercosporin Photochem. Photobiol. 55:373-379.

Lousberg, R. C., Weiss, U., Salemink, C., Arnone, A., Merlini, L., and Nasini, G. 1971. The structure of cercosporin, a naturally occurring quinone. J. Chem. Soc. D. 1971:1463-1464.

Macri, F., and Vianello, A. 1979. Photodynamic activity of cercosporin on plant tissues. Plant Cell Environ. 2:267-271.

Marchionatto, J. B. 1947. Parasitic fungi of plants, new or little known in Argentina. Publicaciones Miscelaneas Ministerio de Agricultura No. 3.

Milat, M., and Blein, J. 1995. Cercospora beticola toxins III. Purification, thinlayer and high performance liquid chromatographic analyses. J. Chromatogr. A 699:277-283.

Miller, P. W., and McWhorter, F. P. 1948. A disease of cabbage and other crucifers due to Cercosporella brassicae. Phytopathology 38:893-898.

Mumma, R. O., Lukezic, F. L., and Kelly, M. G. 1973. Cercosporin from Cercospora hayii. Phytochemistry 12:917-922.

Nasini, G., Merlini, L., Andreetti, G. D., Bocelli, G., and Sgarabotto, P. 1982 Stereochemistry of cercosporin. Tetrahedron 38:2787-2796

Ocamb, C. 2014. White leaf spot and gray stem in crucifer seed crops in western Oregon. Oregon State University, Corvallis, OR.

Okubo, A., Yamazaki, S., and Fuwa, K. 1975. Biosynthesis of cercosporin. Agric. Biol. Chem. 39:1173-1175

Okullo'kwany, F. S. 1987. Studies on white leafspot of turnips caused by Cercosporella brassicae (Fautr. and Roum.), Hoehnel. M.S. thesis, University of Canterbury, Christchurch, New Zealand.

Penaud, A. 1987. La maladie des taches blanches du colza. Phytoma 95:23-26.

Petrie, G. A., and Vanterpool, T. C. 1978. Pseudocercosporella capsellae, the cause of white leaf spot and grey stem of cruciferae in Western Canada. Can. Plant Dis. Surv. 58:69-72.

Reyes, A. 1979. First occurrence of a severe white leafspot on Chinese mustard in Canada. Can. Plant Dis. Surv. 59:1-2.

Shim, W. B., and Dunkle, L. D. 2002. Identification of genes expressed during cercosporin biosynthesis in Cercospora zeae-maydis. Physiol. Mol. Plan Pathol. 61:237-248.

Shim, W. B., and Dunkle, L. D. 2003. CZK3, a MAP kinase kinase kinase homolog in Cercospora zeae-maydis, regulates cercosporin biosynthesis, fungal development, and pathogenesis. Mol. Plant-Microbe Interact. 16:760-768.

Steinkamp, M. P., Martin, S. S., Hoefert, L. L., and Ruppel, E. G. 1981 Ultrastructure of lesions produced in leaves oí Beta vulgaris by cercosporin, a toxin from Cercospora beticola. Phytopathology 71:1272-1281.

Tamaoki, T., and Nakano, H. 1990. Potent and specific inhibitors of protein kinase $\mathrm{C}$ of microbial origin. Nat. Biotechnol. 8:732-735.

Tessmann, D., Charudattan, R., and Preston, J. 2008. Variability in aggressiveness, cultural characteristics, cercosporin production and fatty acid profile of Cercospora piaropi, a biocontrol agent of water hyacinth. Plant Pathol. 57:957-966.

Upchurch, R., Rose, M., Eweida, M., and Zuo, W. 2005. Expression of the cercosporin transporter, CFP, in tobacco reduces frog-eye lesion size. Biotechnol. Lett. 27:1543-1550.

Upchurch, R., Walker, D., Rollins, J., Ehrenshaft, M., and Daub, M. 1991. Mutants of Cercospora kikuchii altered in cercosporin synthesis and pathogenicity. Appl. Environ. Microbiol. 57:2940-2945.

Venkataramani, K. 1967. Isolation of cercosporin from Cercospora personata. J. Phytopathol. 58:379-382.

Yamazaki, S., and Ogawa, T. 1972. The chemistry and stereochemistry of cercosporin. Agric. Biol. Chem. 36:1707-1718.

Yamazaki, S., Okubo, A., Akiyama, Y., and Fuwa, K. 1975. Cercosporin, a nove photodynamic pigment isolated from Cercospora kikuchii. Agric. Biol. Chem. 39:287-288.

You, B., Lee, M., and Chung, K. 2008. Production of cercosporin toxin by the phytopathogenic Cercospora fungi is affected by diverse environmental signals. Can. J. Microbiol. 54:259-269. 